\title{
Monitoring land use changing detection maps with MODIS and AVHRR data from 2001 to 2015 in South Asia regions
}

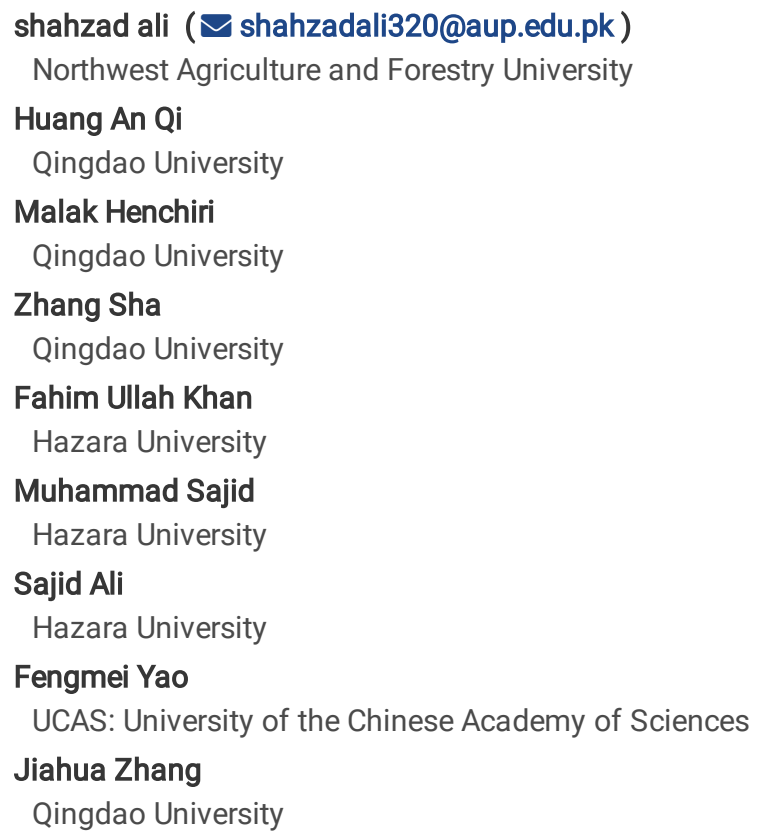

\section{Research Article}

Keywords: Random forest classification, Precision assessment, AVHRR GIMMS NDVI3g, land cover and land use, South Asia

Posted Date: March 9th, 2021

DOI: https://doi.org/10.21203/rs.3.rs-160343/v1

License: (c) (i) This work is licensed under a Creative Commons Attribution 4.0 International License. Read Full License 


\section{Abstract}

In South Asia, annual land cover and land use (LCLU) is a severe issue in the field of earth science because it affects regional climate, global warming, and human activities. Therefore, it is vital essential to obtain correct information on the LCLU in the South Asia regions. LULC annual map covering the entire period is the primary dataset for climatological research. Although the LULC annual global map was produced from the MODIS dataset in 2001, this limited the perspective of the climatological analysis. This study used AVHRR GIMMS NDVI3g data from 2001 to 2015 to randomly forests classify and produced a time series of the annual LCLU map of the South Asia. The MODIS land cover products (MCD12Q1) are used as data from reference for trained classifiers. The results were verified using of the annual map of LCLU time series, and the space-time dynamics of the LCLU map were shown in the last 15 years, from 2001 to 2015 . The overall precision of our 15-year land cover map simplifies 16 classes, which is $1.23 \%$ and $86.70 \%$ significantly maximum as compared to the precision of the MODIS data map. Findings of the past 15 years shows the changing detection that forest land, savanna, farmland, urban and established land, arid land, and cultivated land have increased; by contrast, woody prairie, open shrub-lands, permanent ice and snow, mixed forests, grasslands, evergreen broadleaf forests, permanent wetlands, and water bodies have been significantly reduced over South Asia regions.

\section{Introduction}

Changes in land cover and land use (LCLU) have always remained one of the main concerns in the development of sustainable agricultural management strategies that directly affect the hydrology, biodiversity and local climate (Linke et al., 2009). The LCLU information and its changes over time are very important for assessing the influence on the humans, atmosphere, and world systems (Meyer and Turner, 1992; Di Gregorio, 2005; Ali et al., 2019a). The South Asia is the most affected by land cover and land use change detection (IUCN, 2010; Ali et al., 2019b). The South Asia regions have facing water-related challenges, such as water shortage, low water use efficiency, and degradation of water quality. Furthermore, the South Asia region soon challenged a transition from pastoral-land to farm-land (Schulz et al., 2010; Ali et al., 2019a). The huge impact of land use, land use change and forestry on reducing livestock is another reason, which is related to the restoration of rain-fed farming (Olson et al., 20011). The land use and water resources have been greatly influenced by humans and ecosystems in South Asia have undergone some variations, such as the transformation of wet-lands to dry-lands and the melting of glaciers (Propastin and Muratova, 2008b). In addition, the South Asia regions is covered mostly by grasslands, grasslands savanna, open bushes and nearby bushes are involved in local and global carbon storage (Propastin and Muratova, 2008a). The climate change has been driver by deforestation, function of ecosystems and biodiversity (Tapia-Armijos et al., 2015). In the South Asia regions where natural assets are inadequate, which created an ecological problems in present and future, the forestry sector must improve forest ecosystems based on resources (Laurance et al., 2002).

For climate research, the dataset generated by MODIS (MCD12Q1) was used for LCLU (Lawrence and Chase 2007; Du et al., 2015). Only remote sensing data can provide accurate global LULC for monitoring drought and climate change (Muhammad et al., 2015). The global data set of NOAA-AVHRR images with high temporal frequency and high spatial resolution use to study the land change detection in the South Asia regions (Keith et al., 2014; Liu et al., 2018). In general, the dataset of MODIS is used in combination of dataset of AVHRR to study the land surface conditions on a large scale (James and Kalluri 1994; Jin and Zhang 2019). As described by Friedl et al. (2010) that the images of AVHRR have a continental and global scale old long history. He et al. (2017) reported that due to the accessibility of a higher spatial resolution, higher signal, and better remote-sensing data-sets such as MODIS sensors, the classification of AVHRR data sets has received less attention recently. The AVHRR data set contains the longest global image time series. It deals the probability of generating a time series of LCLU maps for long-term, which is an essential climatological research element. MODIS and AVHRR data are generally combined for land surface conditions and LCLU changing detection maps (Running et al., 1994; Ali et al., 2019a).

In Asia, the South Asia is one of the major important regions, providing a large number of services for economic growth and the world's population, whereas the South Asia contributes only $24 \%$ to the world's population with 3\% world's land area (Bloom and Rosenberg, 2011 ; Fu et al., 2018). The total population increased from 473 million to 1.6 billion during 1950 to 2009 , more than tripled, and is expected to grow by $41 \%$ by the end of 2050 (United Nations, 2009; Henchiri et al., 2019; Du et al., 2015). In the world the south Asia is one of the most ecologically diverse regions (Schneider et al., 2009; Fu et al., 2018; Huang et al., 2017). According to the (http:///://www.cepf. net/) the climatic regions of South Asia are distributed in the high-altitude areas in Afghanistan, in the south Indian Ocean, high mountains in the northwest, Himalayas in the north and the key points of biodiversity in the east of Bangladesh. Recent research has focused on generating a single AVHRR data map, which has not used for large area LCLU maps for time series. However, data-set of AVHRR is an important input for climatological research, and it is possible to generate time series for long-term LULC maps (Herold et al., 2008; Henchiri et al., 2019; Jin et al., 2019). In the present study, since the maximum spatial resolution data of MODIS can be obtained, AVHRR classification is considered to be less (Muhammad et al., 2015; Huang et al., 2017; Liu et al., 2018). The purpose of this study is to produce an annual LCLU map and an analysis of the changing detection between 2001 and 2015 over the South Asia regions. These maps are generated by using the random forest classification technique based on AVHRR GIMMS NDVI3g data set, and land cover product MCD12Q1 by using MODIS data. This study aims to generate a continuous time series covering the annual LCLU map of South Asia from 2001 to 2015, within the lasted 15 years. The spatial comparison of the study area is used to determine the magnitude of the change detection and the LCLU category is determined over the South Asia region.

Page 2/16 


\section{Study Area And Data Sets}

\subsection{Study area}

The study area includes 8 countries in South Asia, ranging from $114^{\circ} 09 \rrbracket-122^{\circ} 43 \varangle \mathrm{E}, 34^{\circ} 22 \rrbracket-38^{\circ} 23 \varangle \mathrm{N}$. South Asia encompasses tropical and subtropical regions, including various climatic zones in the west and north. India and Afghanistan have temperate and arid regions in eastern regions of India and Pakistan. Figure 1 shows the mean sea level, geographic location, and elevation of land cover. From south to north, the elevation of South Asia varies greatly. India represents approximately 18\% (1.3 billion) of the world population and is expected to overtake China in 2024 (United Nations, 2009). India represents approximately 10\% of world agricultural production (Alston and Pardey, 2014) and is expected to be greatly affected by global climate change (Goswami et al., 2006), Overgrowth and overuse of groundwater (Rodell et al. 2012).

\subsection{Data Sets}

The first data set used in this study is the first version of AVHRR GIMMS NDVI3g (2001-2015), which is a bimonthly compound generated from https://ecocast.arc.nasa.gov / data / pub / gimms / 3g.v1 /. According to the research of Pinzon and Tucker (2014), standardized GIMMS $\mathrm{NDVI3g}$ data can be used to solve some problems, such as the impact from the atmosphere, the loss of sensor calibration and orbital floatation. The spatial resolution of the data set is $1 / 12^{\circ}$. Then, we projected the NDVI3g dataset onto a geographic grid with WGS 198 ellipsoids, MODIS MCD12Q1 is the second dataset used in this study, namely WGS 1984 ellipsoids, and re-sampled the initial MCD12Q1 from the MODIS sensor data set. At $1 / 12^{\circ}$ pixels, it is equal to the AVHRR GIMMS NDVI3g dataset (Channan et al., 2014; Na et al., 2020). This data set is used as reference data for AVHRR classification to identify training areas and contains the LULC annual atlas from 2001 to 2015 , corresponding to the classification system of the International Geosphere-Biosphere Project (IGBP).

\subsection{Pre-processing of data}

\subsubsection{Classification}

The study area includes large types of landforms, as well as ecological and climatic settings. Our goal is to select training data to classify it to capture geographic and temporal changes and detect changes in LCLU. We follow He et al., (2017) for the classification and evaluation of precision. Table 1 shows the LULC pixels unchanged in each area. To some extent, LCLU types were excluded from further analysis, reducing the original 17 classes to 16 LCLU classes. Forest randomization consists of a large number of classification trees, which vote on the results of each pixel (He et al., 2017). In addition to the classifier estimates the importance of each variable by summarizing the precision of the tree that does not use that variable (He et al., 2017).

\subsubsection{Accuracy assessment and comparison}

We have chosen several methods to calculate the reliability of the 15-year time series classified maps of the LULC map and represent such a complex dataset. This includes 75\% of the validation data for comparison; the total duration is from 2001 to 2015 , and the MCD12Q1 LULC mapping product was used in the classification of the training data. Tucker et al. (2005) showed that this evaluation can significantly introduce information on the successful replication of AVHRR NDVI. The usual model indicates that the sensor has the spectral advantages and radiation resolution of MODIS data.

\subsubsection{Kappa statistics}

Kappa statistics were also performed to determine the categorization precision of all the elements in the confusion matrix (Pontus and Millones, 2011). Further comparisons, there is a call to normalize the confusion matrix to unify the sum of each row and column (Warren, 2015).

The Kappa statistics calculation formula is as follows. See formula 1 in the supplementary files.

Where $\mathrm{N}=$ samples in the matrix, $\mathrm{r}=$ rows in the matrix, $\mathrm{Xii}$ is the number in the $\mathrm{i}$-th row and the $\mathrm{i}$-th column, $\mathrm{X}+\mathrm{i}$ is the total number in the $\mathrm{i}$-th row, and $\mathrm{Xi}+$ is the total number in the $\mathrm{i}$-th column.

\subsubsection{Land cover and use changing detection}

Post-classification detection technology is used to detect changes in land use and coverage. Use pixel-based comparisons to generate pixel-bypixel change information. To find-out the qualitative and quantitative change from 2001-2005, 2005-2010 and 2010-2015, a cross table was used to evaluate the classified image pairs.

\section{Results And Discussion}

\subsection{Accuracy assessment and comparison}


First, we evaluated the reliability of the classification of the AVHRR data. This is done by comparing the 75\% validation data and LUDIS mapping associations of the MODIS during 2001, 2005, 2010, and 2015 products. These comparisons with MODIS data and 75\% validation data are based on AVHRR classification have 16 categories presented in Table 1. After comparison, we report the results of more routine precision assessments. In the following sections, we summarize geographic and temporal trends from the 15-year time series after the precision assessment. In addition, we present the results of the precision assessment based on 9 LCLU visual interpretation classes. We describe the changes in the LCLU test after the precision assessment. We describe the changes in the LCLU test after the precision assessment. The focus of change detection analysis is the area of land distributed in the last 15 years.

\subsection{LC LU classification with MODIS MCD12Q1 compared}

The consistency value of the year used for classifier training is> 75\% (Figure 1). In training the classifier, we used several years to compare the entire MCD12Q1 chart. The results show that the classifier can infer different years from those used in training. Potentially, this can give information on the degree of success of AVHRR data-set in reproducing the general pattern recognized by MODIS having a sensor with excellent radiation and spectral resolution. To further study the consistency of each LCLU class among these two data sets, we provided producer and user constancy time series for each type of LCLU class from 2001 to 2015 (Figure 2). The year used for training may be different from the annual temperature or precipitation. The consistency of various categories between these two LULC data sets will be further explored. For each category from 2001 to 2015, we show the consistency of the user's time series. The time series is determined as the consistency of the Category I pixels of the entire Category I pixels on the Classification Map, and the producer consistency is determined as Pixels Consistent of Class I pixels. All the pixels of the i-th category in the MODIS data (Figure 2). Each year, the most consistent categories of producers and users are often open bush land, mixed forest, savanna, woody savanna, permanent wetland, grassland, arid and cultivated land. The categories with the least consistency between producers and users are bush land, land cultivated with natural vegetation, permanent ice and snow, bodies of water, urban and construction land. This may be due to the bigger size of the training sample and the better performance of the random forest classification as show in Table 1.

\subsection{LULC classification with $75 \%$ internal comparison verification data}

Identifying possible sources of error and evaluating the quality accuracy of the map is the most excellent approach to obtain such information. Foody, (2002) characterize the precision of the classification outcome derivative from the remote sensing data and the confusion matrix or the error matrix has been converted into a standardized remote sensing tool. The largest category in South Asia clearly shows that the accuracy of producers and users is often unlikely to be affected by cloud pollution. It is worth noting in Table 1 that open shrub-lands, mixed forests, savannas, croplands, permanent wetlands, woody savannas, permanent snow and ice and grasslands tend to cover largest number of training samples with high regional precision. Compared to the consistency value MCD12Q1, the consistency value of our classify map of LCLU is usually lower. Figure 2 summarizes the consistency of the producers and users of LULC that we divided for each class during the study period 2001-2015. Mixed forest, wooded savanna, open shrub-lands, grasslands, savanna, farmland, permanent wetlands, and barren lands are highly consistent, while closed shrub-lands, water bodies, urban and construction lands, permanent snow and ice and natural vegetation mosaics have less (Figure 2). The Kappa coefficients in 2001, 2005, 2010 and 2015 were $86.5 \%, 85.8 \%, 85.5 \%$ and $84.2 \%$, respectively.

\subsection{Change detection analysis}

For a more detailed analysis, we selected the changes in land cover in 2001-2005, 2005-2010 and 2010-2015 with a study interval of five years. Table 2 shows that the category of evergreen coniferous forest decreased by $6,249 \mathrm{~km}^{2}$ during $2001-2005$, then increased by $5,522 \mathrm{~km}^{2}$ from $2005-2010$ and decreased by $18,932 \mathrm{~km}^{2}$ in the last five years of $2010-2015$. The evergreen broadleaf forest category increased by 3,633 $\mathrm{km}^{2}$ during 2001-2005, then increased again by $3,060 \mathrm{~km}^{2}$ during 2005-2010, and decreased by 4,031 km² in the last five years of $2010-2015$. The broadleaf deciduous forest category decreased by $1,716 \mathrm{~km}^{2}$ during 2001-2005, then increased by $7084 \mathrm{~km}^{2}$ during $2005-2010$, and decreased by $26,821 \mathrm{~km}^{2}$ in the last five years of 2010-2015. Between 2001 and 2005, the mixed forest category increased by 13,507 km², between 2005 and 2010 it increased by $8,644 \mathrm{~km}^{2}$ and during the last five years of 2010-2015 it decreased by $37,976 \mathrm{~km}^{2}$. During the period 2001-2005, the category of closed shrub land increased by $1,518 \mathrm{~km}^{2}$, then decreased by $3,426 \mathrm{~km}^{2}$ in $2005-2010$, and increased by $5,543 \mathrm{~km}^{2}$ in the last five years of 2010-2015. The open shrub-lands increase with $24642 \mathrm{Km}^{2}$ during the 2001-2005, and then decreased with 9455 , and 2020 $\mathrm{Km}^{2}$ during the 2005-2010, and 2010-2015. The grasslands increase with $45495 \mathrm{Km}^{2}$ during the 2001-2005, and then decreased with 14804 , and $12794 \mathrm{Km}^{2}$ during the 2005-2010, and 2010-2015. During the 2005-2010, and 2010-2015 the croplands decreased with $16699 \mathrm{Km}^{2}$ during the 2001-2005, and then increased with 2862, and $119800 \mathrm{Km}^{2}$. During the 2010-2015 the permanent snow improved with 1646 , and $14213 \mathrm{Km}{ }^{2}$ during the 2001-2005 and 2005-2010, and then decreased with $81254 \mathrm{Km}^{2}$, respectively. From 2001 to 2015 , the water bodies have decline by 9747,4007 and $20868 \mathrm{~km}^{2}$, respectively.

\subsection{Annual Trends of LCLU over South Asia}

Page $4 / 16$ 
During the 2001, 2005, 2010 and 2015, the annual LULC map of South Asia was generated by random forest classification method are showed in Figure 3. It's worth noting that from 2001 to 2015, the pixels on the LULC map of South Asia did not change in South Asia derived from MCD12Q1 (Figure 1). During the period of land use changing detection, and land change detection during 2001 to 2015 , the map of South Asia was more or less similar. The results obtained indicate that the total area of the survey is $5.07 \times 106 \mathrm{~km}^{2}$ are presented in Table 2 . The area is divided into 16 land cover categories. The cultivated land in South Asia decreased considerably between 2001 and 2005 , and then increased between 2005 and 2015. The significantly reduction of grasslands and the popularization of current agronomic techniques have considerably increased cultivated land (Congalton \& Green, 2009; Yuke, 2019; Na et al., 2020). In the past 15 years, cultivated land in South Asia has increased significantly, while grasslands, forest savannas, broadleaf deciduous forests, bodies of water, and permanent ice and snow have decreased. In contrast, closed bush land, savanna, natural vegetation per capita, barren land, urban land and urbanized in South Asia decreased from 2001 to 2005, but increased from 2005 to 2015 Trend (Table 2). Reddy et al. (2017) confirmed the recent decline of other species and the increase in cultivated land. In this study, the exchange between wetlands, barren areas, and woody shrub-land was significant exchange to crop-lands. In South Asia, compared to other categories, the overall increase and change pattern of cultivated land, our results are similar to those of Yin (2008). However, the basic reason for the basic analysis of various LULC courses in South Asia is beyond the capacity of this article.

Based on above mentioned analysis its confirm the clear spatial change patterns in water bodies, grass-lands, mixed forests, closed shrub-lands, evergreen needle-leaf forests, crop-lands, woody savannas, savannas, open shrub-lands, permanent snow and ice. In Fig. 4, 5, 6, and 7, are indicated the trends of overall 16 categories during the 15 years study period. The trend of the significance was use statistically package by using t-test. The generally trends for water bodies, mixed forests, deciduous broad-leaf forests, croplands, savannas, permanent snow and ice are a significant increase during 2001 to 2015 study duration. While, grass-lands, woody savannas, evergreen broad-leaf forests, closed shrub-lands, evergreen needle-leaf forests, urban lands, permanent wet-lands, open shrub-lands, barren and natural vegetation mosaics are overall showed decrease trend. This is consistent with He et al. (2017). The general crop-lands trend is an improving order from 2001 to 2015 durations. This may be due to change of Green to Grain (Jung et al., 2006; Yao et al., 2017). But, the uncertainty of these trends may be bigger due to larger standard errors of forest and crop-lands compared with grass-lands (Congalton \& Green, 2009). Which may cause due to unusual climate conditions or other pressures and general policy changes (Pinheiro et al., 2014; Zhang et al., 2016; Yuke et al., 2019), our supposition is that these differences might be work of art such as sensor drift as the effect of chronological incompatible differences of GIMMS NDVI data. Earlier research work has indicated also these temporal inconsistencies of GIMMS NDVI value (Klein et al., 2012; Tian et al., 2015).

The confusion or error matrix has become a reliable technique to express the precision of the categorization results derived from remote sensing data (Ibrakhimov et al., 2007; Zhang et al., 2016). The error matrix provides three commonly used precision measures (Foody, 2002; Denisko and Hoffman, 2018), such as producer precision, user precision, and overall (Kotsiantis, 2007; Henchiri et al., 2019). To assess the correctness of the present categorization, we generated a confusion matrix based on the verification data set. Although the selected samples may be spatially related and the training process are not included. The results of the classification in 2001, 2005, 2010 and 2015 showed that the general precision was $87.65 \%, 86.95 \%, 86.67 \%$ and $85.55 \%$. Tables $3,4,5$ and 6 show the confusion matrix for the classification of land cover, respectively.

\section{Conclusion}

The land covered and land use (LCLU) changing detection in South Asia have under major changes, including cultivated land, grasslands, mixed forests, urban and planted forests. The highest precision of producers and users in open shrubs, mixed forests, croplands, grasslands, permanent snow and badlands indicates that separating the categories from the larger reference data allows better random classification of forests. The overall $86.70 \%$ accuracy and $85.48 \%$ is the static kappa value. In addition to user accuracy for deciduous broadleaf forest, producer accuracy for the built-up and urban, water bodies and mosaic is also very small. However, due to the relatively small sample size, the uncertainty in this estimate is quite large. The categories with the highest levels of users and producers ( $>75 \%)$ can be those of mixed forests, savannas and farmland. Tests of change carried out during 2001-2005, 2005-2010 and 2010-2015 showed that during 2001-2015, shrub-lands, barren, croplands, cropland/natural mosaics vegetation, savannas built-up and urban land are increase notably. In contrast, mixed forests, evergreen broadleaf forests, woody savannahs, evergreen coniferous forests, grasslands, permanent wetlands, open shrubs, permanent snow and water notably decrease. The verification and classification techniques used in this research work will be the basic data set for future climate studies, since the study will limit the accessibility of LCLU time series maps.

\section{Declarations}

\section{Acknowledgements and Funding}

This work was supported by the Key basic research project of Shandong natural science foundation of China (ZR2017ZB0422), the China Postdoctoral Science Foundation Project Funding (2018M642614), and “Taishan Scholar” project of Shandong Province. 
The availability of data and materials on the base of personal request.

\section{Authors' contributions}

The manuscript was reviewed and approved for publication by all authors. FY and $\mathrm{JZ}_{\mathrm{Z}}$ conceived and designed the experiments. $\mathrm{SA}^{1}$ and $\mathrm{MH}$ performed the experiments. SA ${ }^{1}, \mathrm{ZS}$,FUK, MS, SA ${ }^{2}$ and $\mathrm{MH}$ analyzed the data. SA ${ }^{1}$ and HAQ wrote the paper. SA ${ }^{1}$, MH, ZS, FH, FY and JZ reviewed and revised the paper.

\section{Compliance with ethical standards}

Conflict of interest

The authors declare that they have no conflict of interest.

\section{Ethical approval}

The manuscript was reviewed and ethical approved for publication by all authors.

\section{Consent to participate}

The manuscript was reviewed and consents to participate by all authors.

\section{Consent to publish}

The manuscript was reviewed and consents to publish by all authors.

\section{References}

Ali, S., Deming, T., Zhen, T. X., Malak, H., Kalisa, W., Shi, S., Jiahua, Z. 2019a. Characterization of drought monitoring events through MODIS and TRMM-based DSI and TVDI over South Asia during 2001-2017. Environmental Science and Pollution Research. doi.org/10.1007/s11356-01906500-4.

Ali, S., Zhen, T. X., Henchiri, M., Wilson. K., Jiahua, Z. 2019b. Studying of drought phenomena and vegetation trends over South Asia from 1990 to 2015 by using AVHRR and NASA's MERRA data. Environmental Science and Pollution Research. doi.org/10.1007/s11356-019-07221-4.

Alston, Julian M, \& Pardey, Philip G. 2014. Agricultural r\&d, food prices, poverty and malnutrition redux. staff papers.

Andres, L., Salas,W.A., Skole, D., 1994. Fourier analysis of multi-temporal AVHRR data applied to a land cover classification. Int. J. Remote Sens. $15,1115-1121$.

Aronoff, S., 1985. The minimum accuracy value as an index of classification accuracy. Photogrammetric Engineering and Remote Sensing, 51, 99-111.

Baudron, P., Alonso-Sarría, F., García-Aróstegui, J.L., Cánovas-García, F., Martínez-Vicente, D., Moreno-Brotóns, J., 2013. Identifying the origin of groundwater samples in a multi-layer aquifer system with random Forest classification. J. Hydrol. 499, 303-315.

Bloom, D.E., Rosenberg, L., 2011. The Future of South Asia: Population Dynamics, Economic Prospects, and Regional Coherence. WDA-Forum, University of St. Gallen. http://www.cepf.net.

Breiman, L., 2001. Random forests. Mach. Learn. 45, 5-32.

Channan, S., Collins, K., Emanuel, W., 2014. Global Mosaics of the Standard MODIS Land Cover Type Data. University of Maryland and the Pacific Northwest National Laboratory, College Park, Maryland, USA.

Congalton, R. G., \& Green, K. 2009. Assessing the accuracy of remotely sensed data: Principles and practices. Lewis Publishers.

Czaplewski, R. L., 1992. Misclassification bias in areal estimates. Photo-grammetric Engineering and Remote Sensing, 58, $189-192$.

Dahinden, C., 2011. An improved random forest approach with application to the performance prediction challenge datasets. Hands-on Pattern Recognition, Challenges in Machine Learning. 1, pp. 223-230.

Dappen, P., 2003. Using Satellite Imagery to Estimate Irrigated Land: A Case Study in Scotts Bluff and Kearney Counties. Center of Advanced Land Management Information Techonologies. University of Nebraska-Lincoln, NE,USA. 
Denisko, D., Hoffman, M.M., 2018. Classification and interaction in random forests. Proc. Natl. Acad. Sci. U. S. A. 115, 1690-1692.

Dhiraj Goswami, Kun-han Tsai, Mark Kassab, \& Takeo Kobayashi. 2006. At-speed testing with timing exceptions and constraints-case studies.

Di Gregorio, A. 2005. Land cover classification system (LCCS), classification concepts and user manual, software version 2. Rome: Food and Agriculture Organization (FAO) of the United Nations.

Du, J., Shu, J., Xinjie, J., Jiaerheng, A., Xiong, S., He, P., Liu, W. 2015. Analysis on spatio-temporal trends and drivers in vegetation growth during recent decades in Xinjing, China. Int J Appl Earth Obs Geoinf 38: 216-228

El Saleous, N., 2005. An extended AVHRR 8-km NDVI dataset compatible with MODIS and SPOT vegetation NDVI data. Int. J. Remote Sens. 26, 4485-4498.

Foody, G. M. 2002. Status of land cover classification accuracy assessment. Remote Sensing of Environment, 80, $185 \mathrm{e} 201$.

Friedl,M.A., Sulla-Menashe, D., Tan, B., Schneider, A., Ramankutty, N., Sibley, A., Huang, X., 2010. MODIS collection 5 global land cover: algorithm refinements and characterization of new datasets. Remote Sens. Environ. 114, 168-182.

Fu, Q., Zhou, Z. Q., Li, T. X., Liu, D., Hou, R. J., Cui, S., Yan, P. R. 2018. Spatiotemporal 10 characteristics of droughts and floods in northeastern China and their impacts on agriculture. Stoch. Environ. Res. Risk Assess. (10), 2913-2931.

He, Y., Lee, E., Timothy, A. W. 2017. A time series of annual land use and land cover maps of China from1982 to 2013 generated using AVHRR GIMMS NDVI3g data. Remote Sensing of Environment 199: 201-217.

Henchiri, M., Ali, S., Bouajila, E., Wilson, K., Sha, Z., Yun, B. 2019. Monitoring land cover change detection with NOAA-AVHRR and MODIS remotely sensed data in the North and West of Africa from 1982 to 2015. Environmental Science and Pollution Research. doi.org/10.1007/s11356-01907216-1.

Herold, D., Mayaux, P., Woodcock, C. E., Baccini, A., \& Schmullius, C. 2008. Some challenges in global land cover mapping: an assessment of agreement and accuracy in existing $1 \mathrm{~km}$ datasets. Remote Sensing of Environment, 112, 2538e2556.

Holben, B.N., 1986. Characteristics of maximum-value composite images from temporal AVHRR data. Int. J. Remote Sens. 7, 1417-1434.

Huang, S. Z., Ming, B., Huang, Q., Leng, G.Y., Hou, B. B. 2017. A Case Study on a Combination NDVI Forecasting Model Based on the Entropy Weight Method. Water Resour. Manag. 34, 3667-3681.

Ibrakhimov, m., Khamzina, A., Forkutsa, I., Paluasheva, G., Lamers, J. P. A., Tischbein, B., et al. 2007. Groundwater table and salinity: spatial and temporal distribution and influence on soil salinization in Khorezm region (Uzbekistan, Aral sea basin). Irrigation and Drainage Systems, 21, $219 \mathrm{e} 236$.

IUCN, International Union for Conservation of Nature. 2010. The Kazakh Steppe e Conserving the world's largest dry steppe region. http://www.iucn.org/about/ union/secretariat/offices/europe/resources/?5640/Kazakh-Action-Plan-for-Grasslands Accessed 10.02.12.

James, M., Kalluri, S.N., 1994. The pathfinder AVHRR land data set: an improved coarse resolution data set for terrestrial monitoring. Int. J. Remote Sens. 15, 3347-3363.

Jin, J., Zhang, N. G. 2019. Temporal and spatial evolution of drought index in Tibet. Soil and water conservation research (05), $377-380$ doi:10.13869/j.cnki.rswc.2019.05.054.

Jung, M., Henkel, K., Herold, M., \& Churkina, G. 2006. Exploiting synergies of global land cover products for carbon cycle modeling. Remote Sensing of Environment, 101, 534e553.

Keith, D. J. , Schaeffer, B. A. , Lunetta, R. S. , Jr, R. W. G. , Rocha, K. , \& Cobb, D. J. 2014. Remote sensing of selected water-quality indicators with the hyperspectral imager for the coastal ocean (hico) sensor. International journal of remote sensing, 35(9-10), 2927-2962.

Klein, I., Ursula, G., Claudia, K. 2012. Regional land cover mapping and change detection in Central Asia using MODIS time-series. Applied Geography; 35, $219 \mathrm{e} 234$.

Kotsiantis, S. B. 2007. Supervised machine learning: a review of classification techniques. Informatica, 31, $249 \mathrm{e} 268$.

Laurance, W.F., Albernaz, A.K., Schroth, G., Fearnside, P.M., Bergen, S., Venticinque, E.M., Da Costa, C. 2002. Predictors of deforestation in the Brazilian Amazon. J. Biogeogr. 29, 737-748. 
Lawrence, P.J., Chase, T.N., 2007. Representing a new MODIS consistent land surface in the Community Land Model (CLM 3.0). J. Geophys. Res. Biogeosci. 112 G01023.

Liaw, A.,Wiener,M., Breiman, L., Cutler, A., 2009. Package “Randomforest”.

https://cran.rproject.org/web/packages/randomForest/randomForest.pdf Accessed 16. 04. 12.

Linke, J., McDermid, G.J., Laskin, D.N., McLane, A.J., Pape, A., Cranston, J., Hall-Beyer, M., Franklin, S.E. 2009. A disturbance-inventory framework for flexible and reliable landscape monitoring. Photogramm. Eng. Remote Sens. 75, 981-995.

Liu, H., Zhang, M., Lin, Z., Xu, X. 2018. Spatial heterogeneity of the relationship between vegetation dynamics and climate change and their driving forces at multiple time scales in southwest china. Agricultural and Forest Meteorology, s256-257, 10-21.

Liu, J., Heiskanen, J., Aynekulu, E., Maeda, E.E., Pellikka, P.K. 2016. Land cover characterization inWest Sudanian Savannas using seasonal features from annual Landsat time series. Remote Sens. 8, 365.

Lunetta, R.S., Knight, J.F., Ediriwickrema, J., Lyon, J.G., Worthy, L.D. 2006. Land-cover change detection using multi-temporal MODIS NDVI data. Remote Sens. Environ. 105, 142-154.

Mertens, B., Lambin, E. 2000. Land-cover-change trajectories in southern Cameroon. Ann. Assoc. Am. Geogr. 90 (3), $467-494$.

Meyer, W. B., \& Turner, I. I.,B. L. 1992. Human population growth and global land use/land cover change. Annual Review of Ecology and Systematics, 23, 39e61.

Muhammad, S., Niu, Z., Wang, L., Aablikim, A., Hao, P., Wang, C., 2015. Crop classification based on time series MODIS EVI and ground observation for three adjoining years in Xinjiang. Spectrosc. Spectr. Anal. 35, 1345-1350.

Na, L., Haixia, L., Tian, x. W., Yi, L., Yi, L., Xinguo, C., Xiao, t. H. 2020. Impact of climate change on cotton growth and yields in Xinjiang, China. Field Crops Research 247(2020) 107590.

Olofsson, P., Foody, G.M., Herold, M., Stehman, S.V., Woodcock, C.E., Wulder, M.A. 2014. Good practices for estimating area and assessing accuracy of land change. Remote Sens. Environ. 148, 42-57.

Olson, D. M., Dinerstein, E., Wikramanayake, E. D., Burgess, N. D., Powell, G. N., Underwood, M. C. 2001. Terrestrial eco-regions of the world: a new map of life on earth. BioScience, 51, 933e938.

Pinheiro, J., Bates, D., DebRoy, S., Sarkar, D. 2014. Package "nlme". https://cran.r-project. org/web/packages/nlme/nlme.pdf Accessed 16. 12. 02.

Pinzon, J.E., Tucker, C.J. 2014. A non-stationary 1981-2012 AVHRR NDVI3g time series. Remote Sens. 6, 6929-6960.

Piper, S. E., 1983. The evaluation of the spatial accuracy of computer classification. In: Proceedings of the 1983 Machine Processing of Remotely Sensed Data Symposium. West Lafayette: Purdue University, 303- 310.

Pontius, R.G., Millones, M. 2011. Death to Kappa: birth of quantity disagreement and allocation disagreement for accuracy assessment. Int. J. Remote Sens. 32, 4407-4429.

Propastin, P. A., Kappas, M., \& Muratova, N. R. 2008a. Inter-annual changes in vegetation activities and their relationship to temperature and precipitation in Central Asia from 1982 to 2003. Journal of Environmental Informatics, 12(2), 75 e87.

Propastin, P. A., Kappas, M., \& Muratova, N. R. 2008b. A remote sensing based monitoring system for discrimination between climate and humaninduced vegetation change in Central Asia. Management of Environmental Quality: An International Journal, 19(5), 579e596.

Reddy, C.S., Pasha, S.V., Satish, K.V., Saranya, K.R.L., Jha, C.S., Krishna Murthy, Y.V.N., 2017. Quantifying nationwide land cover and historical changes in forests of Nepal (1930-2014): implications on forest fragmentation. Biodivers. Conserv. http://dx. doi.org/10.1007/s10531-017$1423-8$.

Rodell, M., Chen, J. , Kato, H. , Nigro, F. J. , \& Al., E. 2012. Grace and water loss from indo-ganga basin. Journal of the Geological Society of India.

Rodriguez-Galiano, V.F., Ghimire, B., Rogan, J., Chica-Olmo, M., Rigol-Sanchez, J.P. 2012. An assessment of the effectiveness of a random forest classifier for land-cover classification. ISPRS J. Photogramm. Remote Sens. 67, 93-104.

Rosenfield, G. H., \& Fitzpatrick-Lins, K. 1986. A coefficient of agreement as a measure of thematic classification accuracy. Photo-grammetric Engineering and Remote Sensing, 52, 223-227. 
Rouse Jr., J.W., Haas, R., Schell, J., Deering, D. 1974. Monitoring Vegetation Systems in the Great Plains with ERTS. Proceedings of the Thrid ERTS Symposium, NASA, Washington, DC, USA, pp. 309-317.

Running, S.W., Loveland, T.R., Pierce, L.L., 1994. A vegetation classification logic based on remote sensing for use in global biogeochemical models. Ambio 23, 77-81.

Sabins, J., Lulla, K. 2007. Remote Sensing: Principles and Interpretation. 3rd edition. Waveland, Illinois.

Schneider, A., Friedl,M.A., Potere, D. 2009. A new map of global urban extent from MODIS satellite data. Environ. Res. Lett. 4, 044003.

Schulz, J.J., Cayuela, L., Echeverria, C., Salas, J., Benayas, J.M.R. 2010. Monitoring land cover change of the dry-land forest landscape of Central Chile (1975-2008). Appl. Geogr. 30 (3), 436-447.

Tapia-Armijos, M.F., Homeier, J., Espinosa, C.I., Leuschner, C., de la Cruz, M. 2015. Deforestation and forest fragmentation in South Ecuador since the 1970s - losing a hotspot of biodiversity. PLoS One 10 (9), e0133701. http://dx.doi.org/10.1371/ journal.pone.0133701.

TEI Saleous, N. 2005. An extended AVHRR 8-km NDVI dataset compatible with MODIS and SPOT vegetation NDVI data. Int. J. Remote Sens. 26, 4485-4498.

Tian, F., Fensholt, R., Verbesselt, J., Grogan, K., Horion, S., Wang, Y. 2015. Evaluating temporal consistency of long-term global NDVI datasets for trend analysis. Remote Sens. Environ. 163, 326-340.

Townshend, J., Justice, C., Li,W., Gurney, C., McManus, J., 1991. Global land cover classification by remote sensing: present capabilities and future possibilities. Remote Sens. Environ. 35, 243-255.

Tucker, C.J., Pinzon, J.E., Brown, M.E., Slayback, D.A., Pak, E.W., Mahoney, R., Vermote, E.F.,

United Nations, 2009. World population prospects: The 2008 revision population database. http://esa.un.org/wup2009/unup/index.asp, Accessed date: 3 October 2015.

Warrens, M.J. 2015. Properties of the quantity disagreement and the allocation disagreement. Int. J. Remote Sens. 36, $1439-1446$.

Wulder, M.A., White, J.C., Loveland, T.R., Woodcock, C.E., Belward, A.S., Cohen, W.B., Fosnight, G., Shaw, J., Masek, J.G., Roy, D.P. 2016. The global Land-sat archive: status, consolidation, and direction. Remote Sens. Environ.

Yao, T.D., Chen, F. H., Cui, P. et al. 2017. From Tibetan Plateau to Third Pole and Pan-Third Pole. Bulletin of Chinese Academy of Sciences, 32, 924931.

Yin, X. 2008. Analysis on the change of land use by remote sensing technology in Manas county. J. Shihezi Univ. (Nat. Sci.) 26, $402-406$.

Yuan, F., Sawaya, K.E., Loeffelholz, B.C., Bauer, M.E. 2005. Land cover classification and change analysis of the Twin Cities (Minnesota) Metropolitan area by multi-temporal Land-sat remote sensing. Remote Sens. Environ. 98, 317-328.

Yuke, Z., 2019. Characterizing the spatio-temporal dynamics and variability in climate extremes over the Tibetan plateau during 1960-2012. J. Resour. Ecol. 10 (4), 397. https://doi.org/10.5814/j.issn.1674-764x.2019.04.007.

Zhang, J., Mu, Q., Huang, J. 2016. Assessing the remotely sensed drought severity index for agricultural drought monitoring and impact analysis in North China. Ecol Indic 63:296-309.

\section{Tables}

\section{Table 1}

Number of pixels for each unchanged LULC type in the study area, with $25 \%$ used for training, and $75 \%$ for validation. 


\begin{tabular}{lcl}
\hline \multicolumn{1}{c}{ MODIS MCD12Q1 class } & Number of pixels & Class for AVHRR classification \\
\hline Evergreen Needleleaf Forests & 128473 & Evergreen Needleleaf Forests \\
\hline Evergreen Broadleaf Forests & 51004 & Evergreen Broadleaf Forests \\
\hline Deciduous Needleleaf Forests & 0 & Deciduous Needleleaf Forests \\
\hline Deciduous Broadleaf Forests & 81789 & Deciduous Broadleaf Forests \\
\hline Mixed Forests & 114 & Mixed Forests \\
\hline Closed Shrublands & 196012 & Closed Shrublands \\
\hline Open Shrublands & 140998 & Open Shrublands \\
\hline Woody Savannas & 160523 & Woody Savannas \\
\hline Savannas & 544814 & Savannas \\
\hline Grasslands & 18647 & Grasslands \\
\hline Permanent Wetlands & 2041977 & Permanent Wetlands \\
\hline Croplands & 43052 & Croplands \\
\hline Urban and Built-up Lands & 56560 & Urban and Built-up Lands \\
\hline Cropland/Natural Vegetation Mosaics & 19456 & Cropland/Natural Vegetation Mo-saics \\
\hline Permanent Snow and Ice & 849519 & Permanent Snow and Ice \\
\hline Barren & 27942 & Barren \\
\hline Water Bodies & 7105 & Water Bodies \\
\hline
\end{tabular}

Table 2

\begin{tabular}{|c|c|c|c|c|c|c|c|c|c|c|c|}
\hline \multirow[t]{2}{*}{ Map unit } & \multicolumn{2}{|c|}{ Area 2001} & \multicolumn{2}{|c|}{ Area 2005} & \multicolumn{2}{|c|}{ Area 2010} & \multicolumn{2}{|c|}{ Area 2015} & \multicolumn{3}{|c|}{ change detection area $\mathrm{km}^{2}$} \\
\hline & $\mathrm{km}^{2}$ & $\%$ & $\mathrm{~km}^{2}$ & $\%$ & $\mathrm{~km}^{2}$ & $\%$ & $\mathrm{~km}^{2}$ & $\%$ & $\begin{array}{l}2001- \\
2005 \\
\end{array}$ & $\begin{array}{l}2005- \\
2010 \\
\end{array}$ & $\begin{array}{l}2010- \\
2015 \\
\end{array}$ \\
\hline $\begin{array}{l}\text { Evergreen Needleleaf } \\
\text { Forests }\end{array}$ & 60058 & 1.18 & 53809 & 1.06 & 59331 & 1.17 & 40399 & 0.80 & -6249 & 5522 & -18932 \\
\hline $\begin{array}{l}\text { Evergreen Broadleaf } \\
\text { Forests }\end{array}$ & 95840 & 1.89 & 99473 & 1.96 & 102533 & 2.02 & 98502 & 1.94 & 3633 & 3060 & -4031 \\
\hline $\begin{array}{l}\text { Deciduous Broadleaf } \\
\text { Forests }\end{array}$ & 179946 & 3.55 & 178230 & 3.51 & 185313 & 3.65 & 154342 & 3.04 & -1716 & 7084 & -26821 \\
\hline Mixed Forests & 163092 & 3.22 & 176599 & 3.48 & 185243 & 3.65 & 147267 & 2.90 & 13507 & 8644 & -37976 \\
\hline Closed Shrublands & 6388 & 0.13 & 7902 & 0.16 & 4475 & 0.09 & 10018 & 0.20 & 1518 & -3426 & 5543 \\
\hline Open Shrublands & 370436 & 7.30 & 395078 & 7.79 & 385623 & 7.60 & 383596 & 7.56 & 24642 & -9455 & -2027 \\
\hline Woody Savannas & 189413 & 3.73 & 187924 & 3.70 & 181168 & 3.57 & 167886 & 3.31 & -1490 & -6755 & -13282 \\
\hline Savannas & 293316 & 5.78 & 301190 & 5.94 & 292519 & 5.77 & 312510 & 6.16 & 7874 & -8671 & 19990 \\
\hline Grasslands & 688154 & 13.57 & 733649 & 14.46 & 718845 & 14.17 & 706052 & 13.92 & 45495 & -14804 & -12794 \\
\hline Permanent Wetlands & 134840 & 2.66 & 127225 & 2.51 & 139493 & 2.75 & 135997 & 2.68 & -7616 & 12269 & -3496 \\
\hline Croplands & 1504676 & 29.66 & 1487977 & 29.33 & 1490839 & 29.39 & 1610639 & 31.75 & -16699 & 2862 & 119800 \\
\hline $\begin{array}{l}\text { Urban and Built-up } \\
\text { Lands }\end{array}$ & 150653 & 2.97 & 147916 & 2.92 & 137622 & 2.71 & 147334 & 2.90 & -2737 & -10294 & 9712 \\
\hline $\begin{array}{l}\text { Cropland/Natural } \\
\text { Vegetation Mosaics }\end{array}$ & 143226 & 2.82 & 131188 & 2.59 & 122675 & 2.42 & 137981 & 2.72 & -12038 & -8514 & 15307 \\
\hline Permanent Snow and Ice & 83504 & 1.65 & 85150 & 1.68 & 99363 & 1.96 & 18110 & 0.36 & 1646 & 14213 & -81254 \\
\hline Barren & 912125 & 17.98 & 872104 & 17.19 & 884376 & 17.43 & 939655 & 18.52 & -40021 & 12272 & 55279 \\
\hline Water Bodies & 97156 & 1.92 & 87409 & 1.72 & 83402 & 1.64 & 62535 & 1.23 & -9747 & -4007 & -20868 \\
\hline Total & 5072822 & $100 \%$ & 5072822 & $100 \%$ & 5072822 & $100 \%$ & 5072822 & $100 \%$ & & & \\
\hline
\end{tabular}

Land cover/land use classes and change detection areas for each class in $\mathrm{Km}^{2}$.

\section{Table 3}

Confusion matrix of land covers classification 2001, expressed in percentages. 


\begin{tabular}{|c|c|c|c|c|c|c|c|c|c|c|c|c|c|c|c|c|c|}
\hline & \multicolumn{17}{|c|}{ Reference class } \\
\hline & ENF & $\mathrm{EBF}$ & DBF & $\mathrm{MF}$ & $\mathrm{CS}$ & OS & WS & $\mathrm{S}$ & GL & PW & $\mathrm{CL}$ & UBL & NVM & PSI & $\mathrm{B}$ & WB & UA \\
\hline \multicolumn{18}{|l|}{$\begin{array}{l}\text { Mapped } \\
\text { class }\end{array}$} \\
\hline ENF & 85.11 & 1.03 & 0.81 & & & & 0.85 & 0.68 & 0.42 & & 0.53 & & & & & 1.72 & 81.63 \\
\hline $\mathrm{EBF}$ & & 93.81 & 2.44 & 0.61 & & & 2.54 & 1.37 & & 1.49 & & & 1.75 & & & & 84.26 \\
\hline DBF & & 2.06 & 88.62 & 1.82 & & & 3.39 & 4.11 & 0.84 & & & 6.67 & 4.39 & & & 1.72 & 74.66 \\
\hline MF & 6.38 & 1.03 & 2.44 & 95.76 & & & 1.27 & 2.40 & 0.84 & 1.49 & 1.60 & & 1.75 & & & 3.45 & 85.41 \\
\hline CS & & & & & 85.71 & & & & & & & & & & & & 100.00 \\
\hline OS & & & & & & 95.00 & & & 3.78 & 1.49 & & 1.67 & & 1.15 & 4.28 & 1.72 & 89.06 \\
\hline WS & & & 1.63 & & & & 89.41 & 3.08 & & 4.48 & & & 3.51 & & & 1.72 & 91.74 \\
\hline $\mathrm{S}$ & 2.13 & 1.03 & 0.81 & & 14.29 & & 1.69 & 86.64 & 0.84 & 4.48 & 2.66 & 3.33 & 5.26 & & & 1.72 & 90.36 \\
\hline GL & 4.26 & & 0.81 & 0.61 & & 1.11 & & & 89.50 & & 3.19 & 6.67 & 0.88 & & 2.67 & 1.72 & 90.25 \\
\hline PW & & & & & & & & 0.34 & & 85.07 & 1.60 & 8.33 & 2.63 & & & & 82.61 \\
\hline CL & 2.13 & 1.03 & 0.81 & 1.21 & & 0.56 & & 1.03 & 0.84 & 1.49 & 89.89 & 10.00 & 4.39 & 1.15 & 1.60 & 8.62 & 84.08 \\
\hline NVM & & & 1.63 & & & & 0.85 & & & & 0.53 & & 74.56 & & & 1.72 & 93.41 \\
\hline PSI & & & & & & & & & & & & & & 81.61 & 2.14 & & 94.67 \\
\hline B & & & & & & 3.33 & & & 2.94 & & & & & 16.09 & 89.30 & 3.45 & 85.20 \\
\hline WB & & & & & & & & 0.34 & & & & & & & & 72.41 & 97.67 \\
\hline PA & 85.11 & 93.81 & 88.62 & 95.76 & 85.71 & 95.00 & 89.41 & 86.64 & 89.50 & 85.07 & 89.89 & 63.33 & 74.56 & 81.61 & 89.30 & 72.41 & \\
\hline OA & $87.65 \%$ & & & & & & & & & & & & & & & & \\
\hline $\mathrm{KC}$ & $86.51 \%$ & & & & & & & & & & & & & & & & \\
\hline
\end{tabular}

Table 4

Confusion matrix of land covers classification 2005, expressed in percentages.

\begin{tabular}{|c|c|c|c|c|c|c|c|c|c|c|c|c|c|c|c|c|c|}
\hline & \multicolumn{17}{|c|}{ Reference class } \\
\hline & ENF & EBF & DBF & MF & $\mathrm{CS}$ & OS & WS & $\mathrm{S}$ & GL & PW & CL & UBL & NVM & PSI & B & WB & UA \\
\hline \multicolumn{18}{|l|}{$\begin{array}{l}\text { Mapped } \\
\text { class }\end{array}$} \\
\hline ENF & 87.23 & 3.09 & 0.81 & 1.21 & & & 1.69 & 0.68 & 0.42 & 1.49 & 0.53 & & 2.63 & & & & 69.49 \\
\hline EBF & & 92.78 & 0.81 & 2.42 & & & 2.97 & 0.68 & & 1.49 & & & & & & & 85.71 \\
\hline DBF & & & 91.06 & 1.21 & & & 2.97 & 1.37 & 0.84 & 1.49 & 1.60 & 3.33 & 1.75 & & & & 82.96 \\
\hline MF & 8.51 & 1.03 & 2.44 & 92.12 & & & 4.24 & 4.11 & & 2.99 & 0.53 & & 2.63 & & & 3.45 & 80.00 \\
\hline CS & & & & & 85.71 & 0.56 & & & & & & & & & & & 85.71 \\
\hline OS & & & & & & 96.11 & & & 2.94 & & 0.53 & & & 2.30 & 7.49 & 1.72 & 87.37 \\
\hline WS & & & 2.44 & & & & 87.71 & 1.37 & 0.42 & 1.49 & & & 2.63 & & 0.00 & & 94.52 \\
\hline S & 2.13 & 3.09 & & 1.21 & 14.29 & & & 89.04 & & 8.96 & 3.19 & 1.67 & 8.77 & & 0.53 & & 89.35 \\
\hline GL & 2.13 & & 1.63 & 0.61 & & 0.56 & & & 90.76 & 1.49 & 3.72 & 5.00 & 2.63 & & 1.60 & 3.45 & 90.00 \\
\hline PW & & & & 0.61 & & & & 0.34 & & 77.61 & 2.13 & 6.67 & 1.75 & & & & 81.25 \\
\hline CL & & & 0.81 & & & & 0.42 & 1.37 & 2.52 & 2.99 & 87.23 & 6.67 & 5.26 & 1.15 & 1.07 & 10.34 & 83.25 \\
\hline UBL & & & & & & & & 0.34 & & & & 76.67 & 1.75 & & 0.53 & 1.72 & 90.20 \\
\hline NVM & & & & 0.61 & & & & 0.34 & & & 0.53 & & 70.18 & & & 3.45 & 94.12 \\
\hline PSI & & & & & & & & & & & & & & 74.71 & 1.60 & & 95.59 \\
\hline B & & & & & & 2.78 & & & 1.68 & & & & & 21.84 & 87.17 & 8.62 & 83.16 \\
\hline WB & & & & & & & & 0.34 & 0.42 & & & & & & & 67.24 & 95.12 \\
\hline PA & 87.23 & 92.78 & 91.06 & 92.12 & 85.71 & 96.11 & 87.71 & 89.04 & 90.76 & 77.61 & 87.23 & 76.67 & 70.18 & 74.71 & 87.17 & 67.24 & \\
\hline $\mathrm{OA}$ & $86.95 \%$ & & & & & & & & & & & & & & & & \\
\hline KC & $85.75 \%$ & & & & & & & & & & & & & & & & \\
\hline
\end{tabular}

\section{Table 5}

Confusion matrix of land covers classification 2010, expressed in percentages. 


\begin{tabular}{|c|c|c|c|c|c|c|c|c|c|c|c|c|c|c|c|c|c|}
\hline & \multicolumn{17}{|c|}{ Reference class } \\
\hline & ENF & EBF & DBF & $\mathrm{MF}$ & $\mathrm{CS}$ & OS & WS & $\mathrm{S}$ & GL & PW & $\mathrm{CL}$ & UBL & NVM & PSI & $\mathrm{B}$ & WB & UA \\
\hline \multicolumn{18}{|l|}{$\begin{array}{l}\text { Mapped } \\
\text { class }\end{array}$} \\
\hline ENF & 85.11 & 2.06 & 2.44 & 1.82 & & & & 1.37 & 0.42 & & 0.53 & & & & & 3.45 & 71.43 \\
\hline $\mathrm{EBF}$ & & 91.75 & 1.63 & 2.42 & & & 7.20 & 1.03 & 0.42 & & 0.53 & & 2.63 & & & & 74.17 \\
\hline DBF & & & 87.80 & 3.64 & & & 3.81 & 2.40 & 2.10 & 1.49 & 2.66 & 5.00 & 3.51 & & & & 72.97 \\
\hline CS & & & & & 85.71 & 0.56 & & & 0.42 & & & & & & & & 75.00 \\
\hline OS & & & & & & 98.33 & & & 2.10 & 1.49 & 0.53 & & & & 2.67 & & 93.65 \\
\hline WS & & & 1.63 & 0.61 & & & 83.90 & 2.40 & & & 1.06 & & 5.26 & & & 3.45 & 90.83 \\
\hline $\mathrm{S}$ & 2.13 & 2.06 & 1.63 & 0.61 & 14.29 & & 0.85 & 87.67 & 1.26 & 2.99 & 2.13 & 3.33 & 3.51 & & & & 91.43 \\
\hline GL & 4.26 & & 1.63 & 0.61 & & & & & 88.66 & 1.49 & 4.26 & 3.33 & & & 2.14 & 3.45 & 90.56 \\
\hline PW & & 1.03 & & & & & 0.42 & & & 83.58 & 2.66 & 6.67 & 0.88 & & & & 82.35 \\
\hline CL & 2.13 & & & & & 0.56 & & 1.37 & 2.52 & 2.99 & 84.57 & 13.33 & 4.39 & & 0.53 & 6.90 & 83.25 \\
\hline NVM & & 1.03 & 0.81 & & & & & 0.34 & & & 0.53 & & 72.81 & & & & 95.40 \\
\hline PSI & & & & & & & & & & & & & & 80.46 & 0.53 & 1.72 & 97.22 \\
\hline B & & & & & & 0.56 & & & 1.68 & & & & & 19.54 & 94.12 & 5.17 & 87.56 \\
\hline WB & & & & & & & & 0.34 & & & & & & & & 72.41 & 97.67 \\
\hline PA & 85.11 & 91.75 & 87.80 & 90.30 & 85.71 & 98.33 & 83.90 & 87.67 & 88.66 & 83.58 & 84.57 & 66.67 & 72.81 & 80.46 & 94.12 & 72.41 & \\
\hline OA & $86.67 \%$ & & & & & & & & & & & & & & & & \\
\hline $\mathrm{KC}$ & $85.45 \%$ & & & & & & & & & & & & & & & & \\
\hline
\end{tabular}

Table 6

Confusion matrix of land covers classification 2015, expressed in percentages.

\begin{tabular}{|c|c|c|c|c|c|c|c|c|c|c|c|c|c|c|c|c|c|}
\hline & \multicolumn{17}{|c|}{ Reference class } \\
\hline & ENF & EBF & DBF & MF & $\mathrm{CS}$ & OS & WS & $\mathrm{S}$ & GL & PW & $\mathrm{CL}$ & UBL & NVM & PSI & $\mathrm{B}$ & WB & UA \\
\hline \multicolumn{18}{|l|}{$\begin{array}{l}\text { Mapped } \\
\text { class }\end{array}$} \\
\hline ENF & 68.09 & 1.03 & & & & & 1.69 & 0.34 & & & 0.53 & & 0.87 & & & & 80.00 \\
\hline EBF & 2.13 & 93.81 & & 1.82 & & & 2.54 & 1.37 & & & & & & & & & 86.67 \\
\hline DBF & 2.13 & & 93.50 & 5.45 & & & 3.39 & 2.74 & 0.42 & 1.49 & & 1.61 & 6.09 & & & & 76.16 \\
\hline MF & 8.51 & 2.06 & 2.44 & 86.67 & & & 4.66 & 3.08 & 0.42 & & 0.53 & 3.23 & 2.61 & & & & 79.89 \\
\hline CS & & & & & 85.71 & & & & 0.42 & & & & & & & & 85.71 \\
\hline OS & & & & & & 93.26 & & & 2.53 & & 1.06 & 1.61 & & & 3.74 & 5.17 & 89.73 \\
\hline WS & 2.13 & 1.03 & 1.63 & 2.42 & & & 84.75 & 1.03 & 0.00 & & & & 3.48 & & & 1.72 & 92.59 \\
\hline S & 6.38 & 2.06 & 0.81 & 2.42 & 14.29 & & 1.27 & 86.99 & 2.53 & 2.99 & 2.66 & 3.23 & 4.35 & & & & 88.19 \\
\hline GL & 8.51 & & 0.81 & 0.61 & & 2.25 & & & 86.92 & 2.99 & 4.26 & 16.13 & 3.48 & 1.16 & 1.07 & 5.17 & 83.74 \\
\hline PW & & & & & & & & 1.03 & & 83.58 & 1.60 & & 2.61 & & 0.53 & & 84.85 \\
\hline CL & 2.13 & & & & & & 0.85 & 2.05 & 3.38 & 2.99 & 88.30 & 16.13 & 5.22 & & 1.07 & 10.34 & 79.43 \\
\hline UBL & & & & & & & & 0.34 & & & 0.53 & 56.45 & & & & 1.72 & 92.11 \\
\hline NVM & & & 0.81 & 0.61 & & & 0.85 & 0.68 & 0.42 & & & & 71.30 & & & & 92.13 \\
\hline PSI & & & & & & & & & & & & & & 90.70 & & & 100.00 \\
\hline B & & & & & & 3.93 & & & 2.53 & 5.97 & 0.53 & 1.61 & & 8.14 & 93.05 & 22.41 & 81.69 \\
\hline WB & & & & & & 0.56 & & 0.34 & 0.42 & & & & & & 0.53 & 53.45 & 88.57 \\
\hline PA & 68.09 & 93.81 & 93.50 & 86.67 & 85.71 & 93.26 & 84.75 & 86.99 & 86.92 & 83.58 & 88.30 & 56.45 & 71.30 & 90.70 & 93.05 & 53.45 & \\
\hline $\mathrm{OA}$ & $85.55 \%$ & & & & & & & & & & & & & & & & \\
\hline $\mathrm{KC}$ & $84.20 \%$ & & & & & & & & & & & & & & & & \\
\hline
\end{tabular}

\section{Figures}




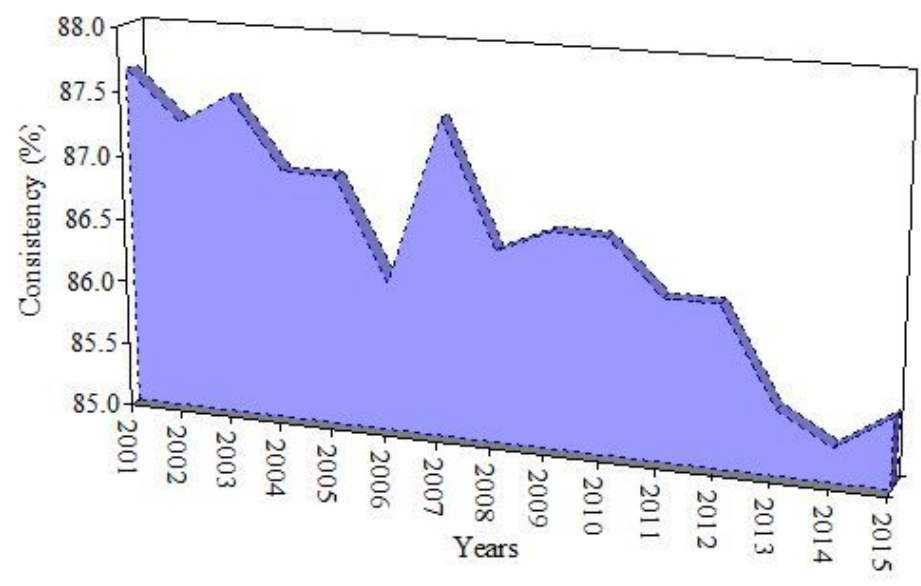

\section{Figure 1}

Consistency between classified LULC maps and MODIS MCD12Q1 from 2001 to 2015.

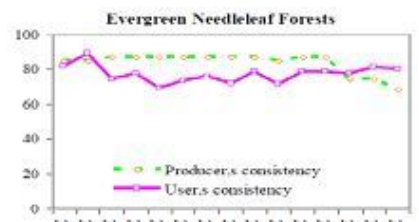

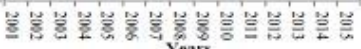

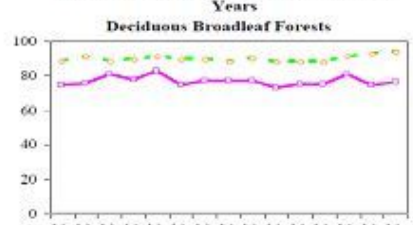

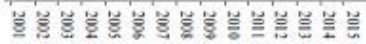

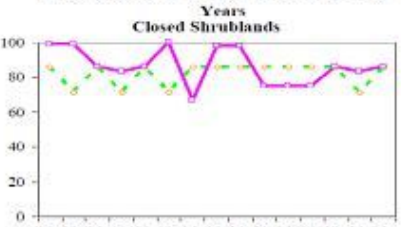

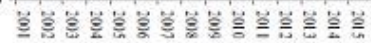
Woody Savanan

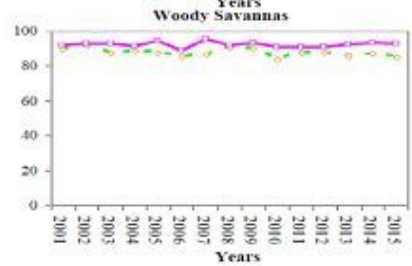

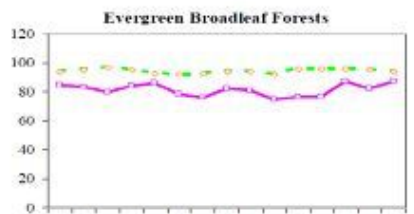
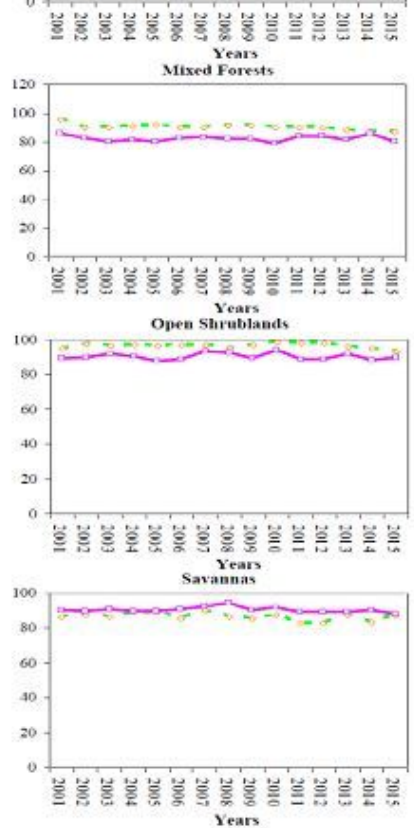

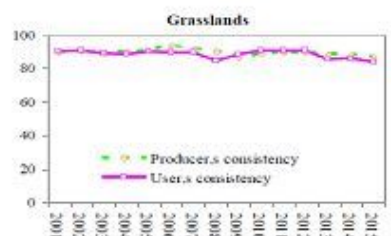

Crophanuls
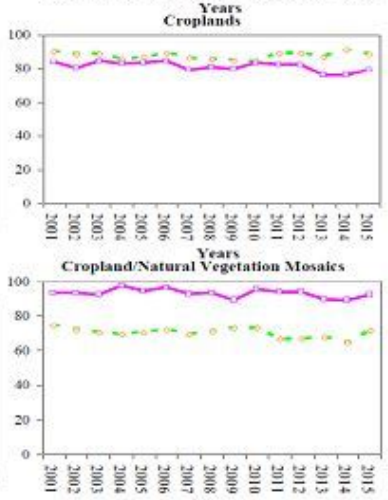

Year,
Barren

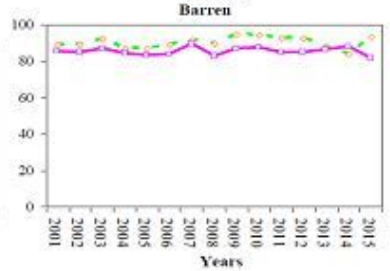

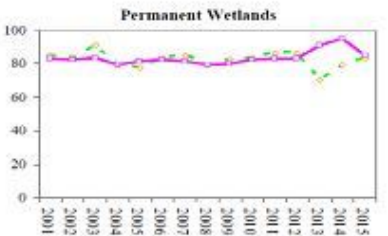

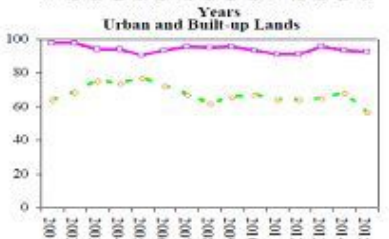

kermaneat Snaws and Ice

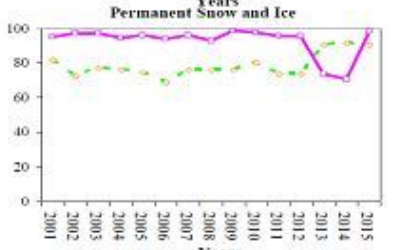

Years
water Bodlies

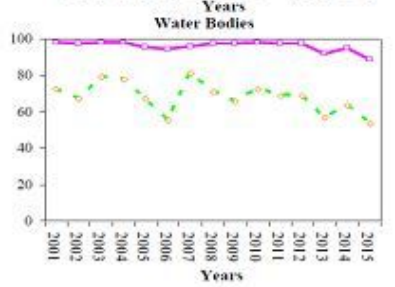

\section{Figure 2}

User's and producer's consistencies for each class between classified LULC maps and MODIS MCD12Q1 from 2001 to 2015. 


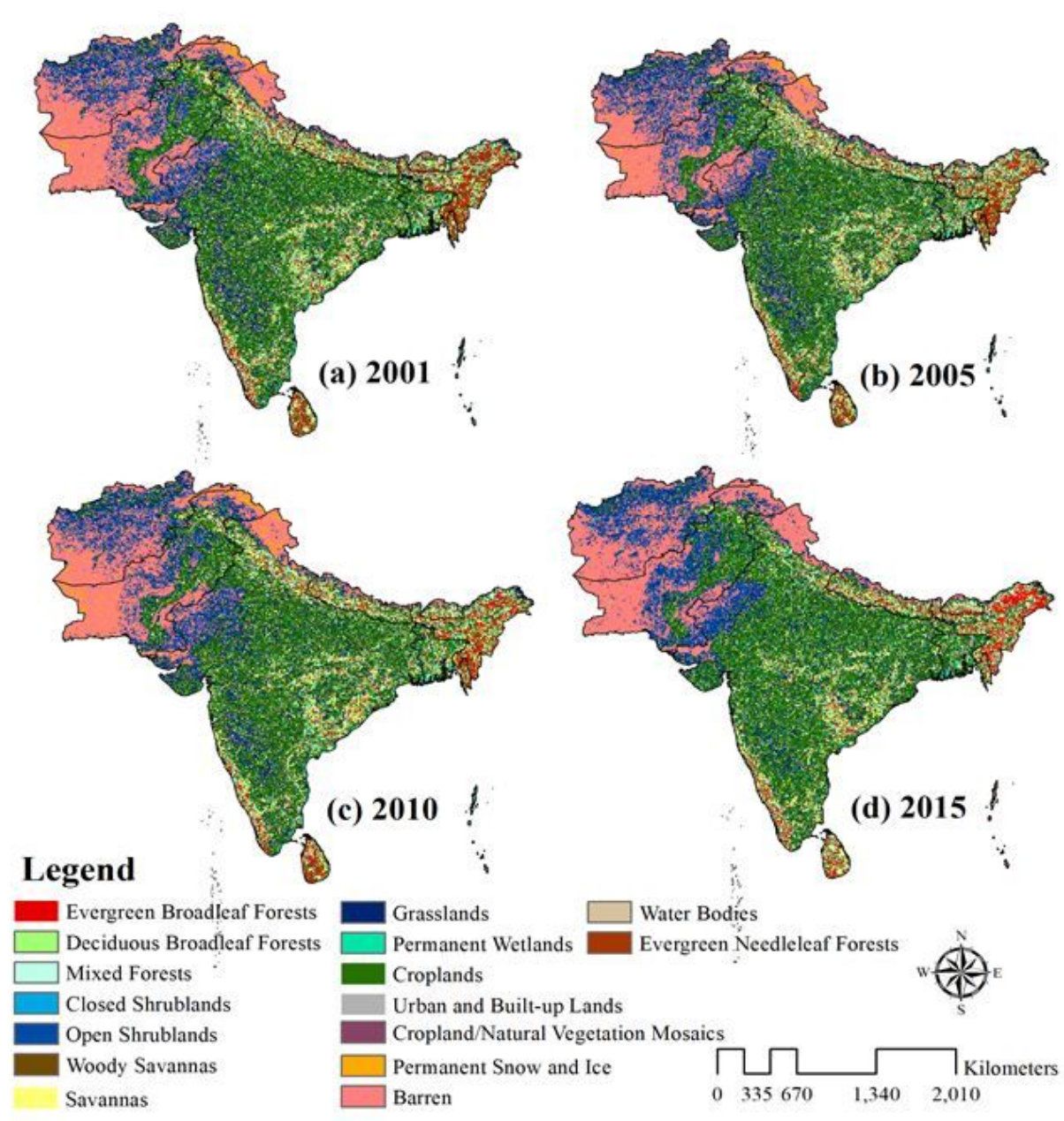

Figure 3

Annual LULC maps of South Asia, produced by random forest classification. (a) 2001, (b) 2005, (c) 2010, and (d) 2015.

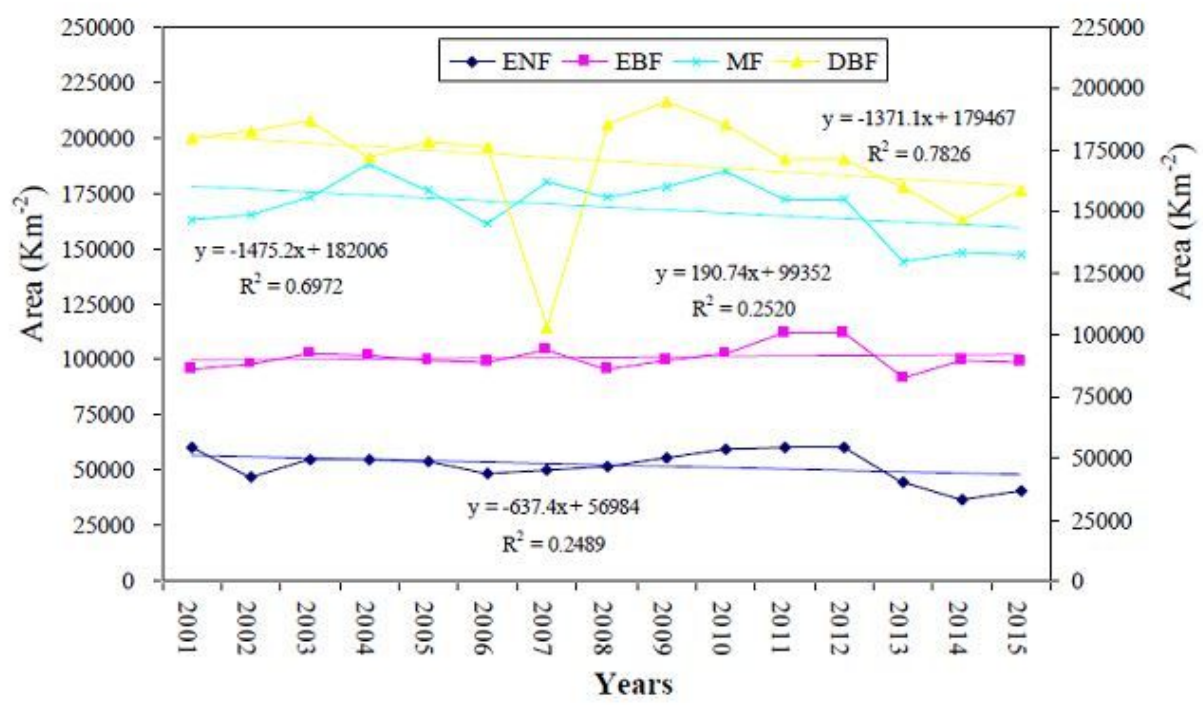

Figure 4

Temporal changes in area of evergreen needleleaf forests (ENF), evergreen broadleaf forests (EBF), mixed forests (MF) and deciduous broadleaf forests (DBF) classes from 2001 to 2015. Dotted lines represent overall trend. 


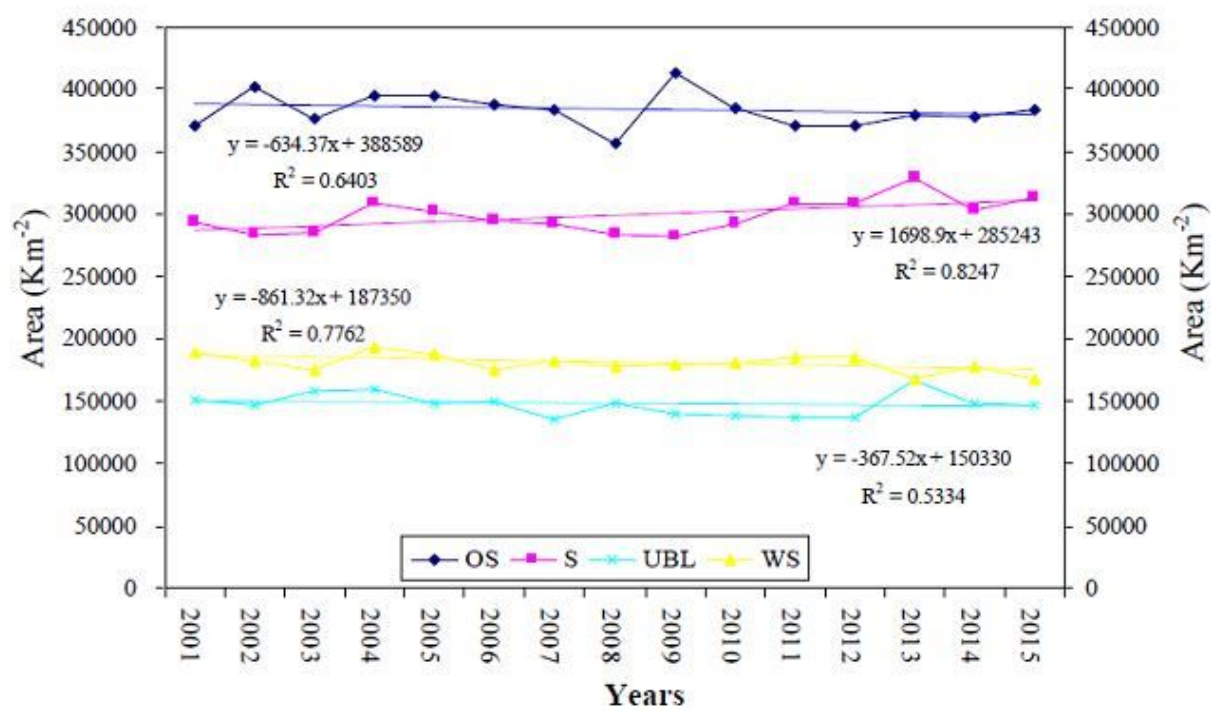

\section{Figure 5}

Temporal changes in area of open shrublands (OS), savannas (S), urban and built-up lands (UBL) and woody savannas (WS) classes from 2001 to 2015. Dotted lines represent overall trend.

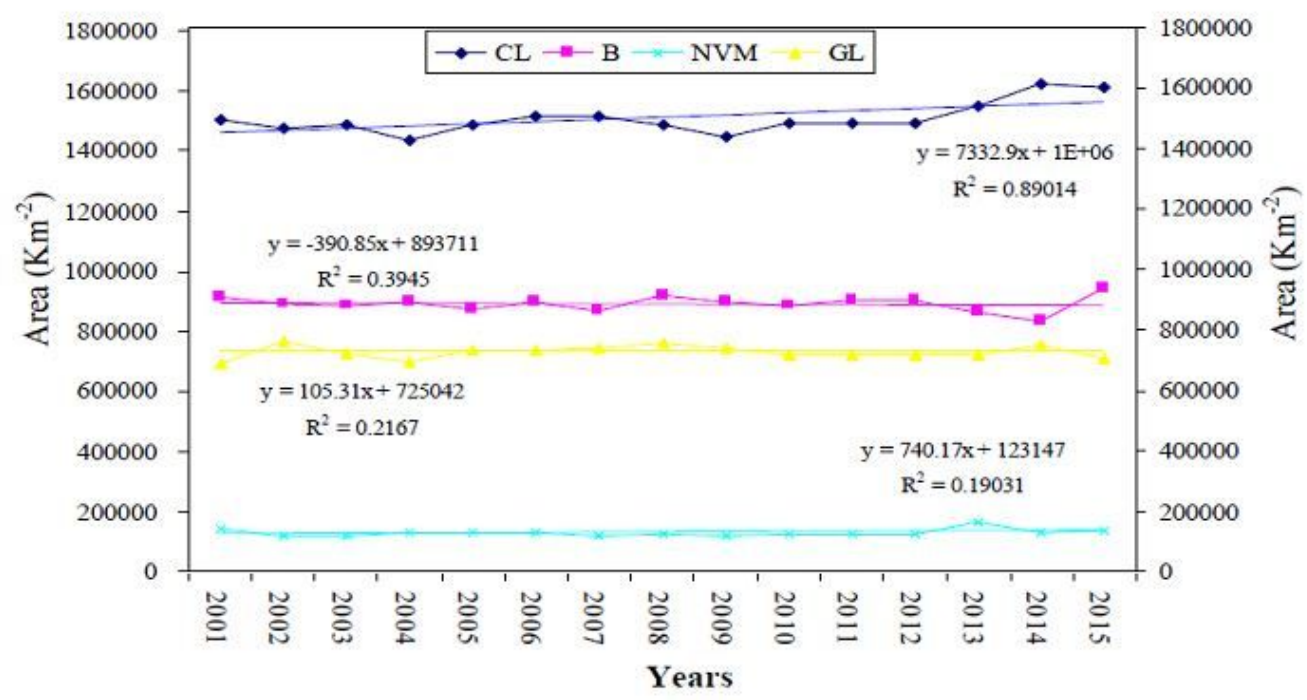

Figure 6

Temporal changes in area of croplands (CL), barren (B), cropland/natural vegetation mosaics (NVM) and grasslands (GL) classes from 2001 to 2015. Dotted lines represent overall trend. 


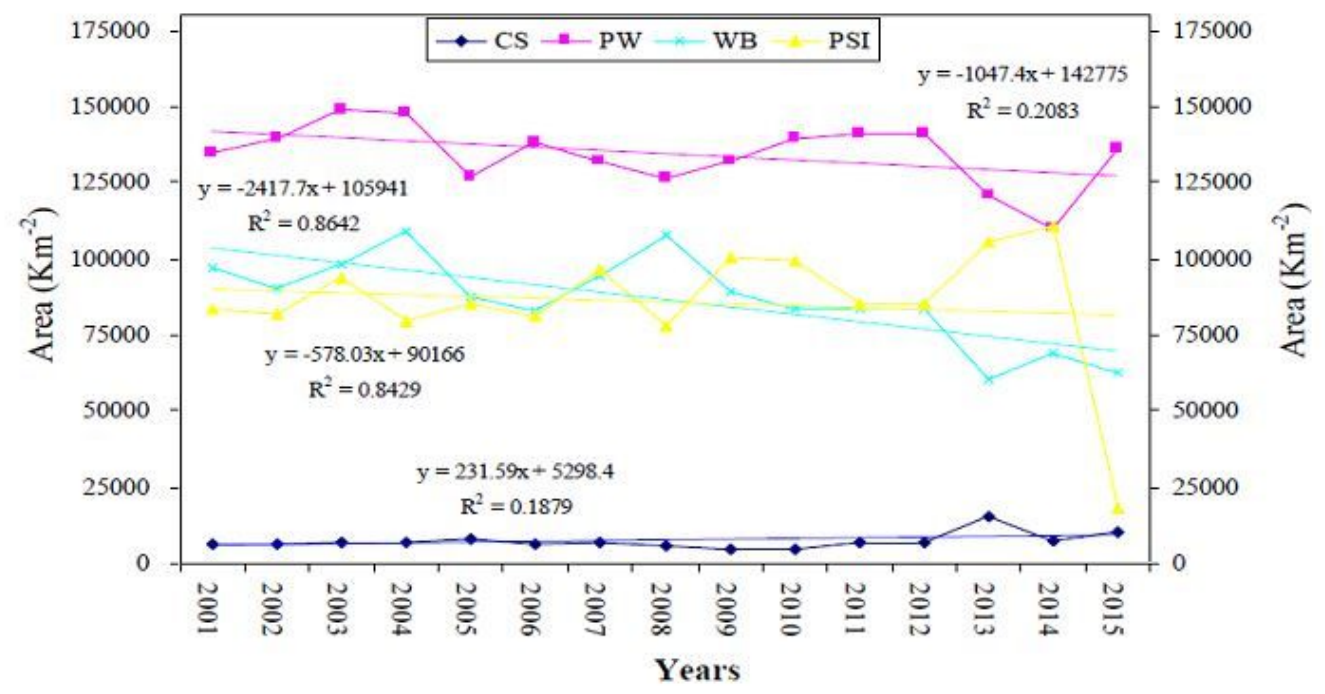

Figure 7

Temporal changes in area of closed shrublands (CS), permanent wetlands (PW), water bodies (WB) and permanent snow and ice (PSI) classes from 2001 to 2015. Dotted lines represent overall trend. 